\title{
Relationship between Maternal Obesity and Congenital Malformation in a Subpopulation of Havana
}

\author{
Rolando A Hernández Fernández ${ }^{1}$, Lizmery Valdés Collazo ${ }^{2}$, Sonia Clapés Hernández ${ }^{3}$ and Araceli Lantigua Cruz ${ }^{4 *}$
}

${ }^{1}$ Full Professor, MD. MS. Department of Biochemistry, Institute for Basic and Preclinical Sciences “Victoria de Girón”, University of Medical Sciences of Havana, Cuba ${ }^{2}$ Postgraduate Student, Department of Biochemistry, Institute for Basic and Preclinical Sciences "Victoria de Girón”, University of Medical Sciences of Havana, Cuba ${ }^{3}$ Full Professor, Department of Biochemistry, Institute for Basic and Preclinical Sciences "Victoria de Girón”, University of Medical Sciences of Havana, Cuba

${ }^{4}$ Full Professor, National Center of Medical Genetics, University of Medical Sciences of Havana, Cuba

\begin{abstract}
Background: The objective of this study was to assess, from the data set recorded in Cuban Record of Congenital Malformations of the National Center for Medical Genetics and Hospital "Eusebio Hernández" in Havana, whether maternal obesity was associated with an increased risk for various structural birth defects.

Methods: This is a retrospective study about relationship between maternal obesity and congenital defects. The study population consisted of 217 new borns and fetuses with congenital malformations in three municipalities of Havana: Lisa, Playa, and Marianao from January 1, 2004, through December 31, 2008. Maternal weight and height data were obtained from the archives of Hospital "Eusebio Hernandez", where the children were born or the pregnancies were interrupted. Women were grouped in four categories of body mass index (BMI) according to the World Health Organization classification
\end{abstract}

Results: About thirty percent $(29.5 \%)$ of the study population was overweight and $14.7 \%$ were obese Cardiovascular defects $(34.4 \%)$ and neural tube defects $(37.5 \%)$ were the most frequent malformations. Other congenital defects were less frequent and maternal overweight does not appear to be associated with them.

Conclusion: Maternal obesity is a risk for congenital defects, especially cardiovascular and neural tube defects. Physicians must keep in mind this situation in order to offer a good prenatal service to obese pregnant woman.

\section{Keywords: Maternal obesity; Congenital Defects; Cuba}

\section{Introduction}

Many years ago, maternal obesity has been identified as a risk for some diseases in the offspring, such as diabetes type 2, insulin resistance and obesity [1] as well as heart defects [2]. There are significant health implications of prepregnancy maternal obesity for both mother and child. For the mother, these may include gestational diabetes, hypertensive disorders, thromboembolic disorders, increased cesarean delivery rates, and wound infection. Infants of obese mothers are at increased risk of birth difficulties, macrosomia, and perinatal death. Maternal obesity may also be associated with the development of congenital anomalies. Congenital anomalies are a leading cause of stillbirth and infant mortality, accounting for 1 in 5 infant deaths in the United States [3].

However, during the last decades, obesity during pregnancy has been related to congenital defects in the offspring. Among them the most frequent reported are neural tube defects [4], cardiovascular malformations [5] and orofacial cleft [6,7]. Furthermore, maternal obesity significantly increases fetal and neonatal adiposity in humans; thus, enhanced adipocyte development per se must play an important role in the genesis of obesity in the offspring [8].

There is no full explanation for this kind of relationship. Obesity induces chronic low-grade inflammation that may be the primary cause of associated diseases. Cellular and molecular mechanisms in acute inflammatory response are well studied. Events involved in chronic inflammation and their physiological consequences are beginning to be appreciated. Inflammatory cells release reactive oxygen species that may cause damage to biomolecules such as lipids, proteins and nucleic acids. These damages could interfere with developmental program of the fetus and result in congenital defects. The steady increase in overweight reproductive age women is correlated with increases in rates of childhood and infant obesity. A possible link between the abnormal intrauterine environment and abnormal growth and development of offspring must be considered [1].

Our group is working on the relationship between pregnancy and obesity and this study is a first approach to estimate how high is the risk for congenital defects in obese pregnant in our country.

\section{Materials and Methods}

The study population consisted of infants born in "Eusebio Hernández" Hospital, January 1, 2004, through December 31, 2008 , with congenital defects, and were registered in the Cuban Record for Congenital Malformations of the National Center for Medical Genetics, RECUMAC (Registro Cubano de Malformaciones Congénitas). The families of the children live in the municipalities of Lisa, Playa, and Marianao from Havana.

Taken into account that there is an extensive program of prenatal diagnosis in Cuba for detecting fetal anomalies and when the study was

*Corresponding author: Araceli Lantigua Cruz, National Center of Medical Genetics, University of Medical Sciences of Havana, Cuba, Tel: 5372720809 ; E-mail: lantigua@infomed.sld.cu

Received November 20, 2014; Accepted January 18, 2014; Published January 22, 2015

Citation: Fernández RAH, Collazo LV, Hernández SC, Cruz AL (2015) Relationship between Maternal Obesity and Congenital Malformation in a Subpopulation of Havana. J Diabetes Metab 6: 498. doi:10.4172/2155-6156.1000498

Copyright: () 2015 Fernández RAH, et al. This is an open-access article distributed under the terms of the Creative Commons Attribution License, which permits unrestricted use, distribution, and reproduction in any medium, provided the original author and source are credited. 
positive most women have decided to end the pregnancy, we accessed the register for pregnancy interruptions in the same period in the charge of the Clinical Geneticist of the area. The intrauterine material was examined systematically by a hospital pathologist. We discarded all fetuses whose diagnosis was other than malformations.

Medical and other data from the mothers were obtained from de clinical records of "Eusebio Hernández" Hospital because all the women of these municipalities receive medical care in this hospital.

Women were classified in four groups according to their body mass index (BMI), as follows: UW: underweight $(\mathrm{BMI}<19.8)$, RW: recommended weight $(19.8<\mathrm{BMI}>24.9)$, OW: overweight $(25<\mathrm{BMI}>29.9)$, and $\mathrm{OB}$ : obese $(\mathrm{BMI}>30)$.

We studied the association between the types of fetal or newborn congenital malformation, and the mother's BMI.

\section{Results}

A total of 217 newborns and fetuses were found in the Cuban Record for Congenital Malformations (RECUMAC) and Clinical Geneticist of the area. Their mothers' BMI are shown in Table 1.

About thirty percent $(29.49 \%)$ of the study population was overweight and $14,74 \%$ were obese. Morbid obesity was not found.

Taken into account that in the study period 14, 481 deliveries took place in the hospital, we can estimate de prevalence at birth as shown in Table 2. The adjusted prevalence includes the number of interruptions.

Table 3 shows the distribution of the most frequent congenital malformations among newborns and fetuses of women who were underweight, recommended weight, overweight, or obese before pregnancy.

Table 4 shows the distribution of less frequent congenital malformations among newborns and fetuses of women who were underweight, recommended weight, overweight, or obese before pregnancy.

\section{Discussion}

Our study confirms that maternal overweight was associated with an increased risk for cardiovascular defects [9], and cardiac defects, in particular transposition of great vessels and septal defects [10]. The risk is higher in obesity pregnant women.

Neural tube defects represent the most frequent anomaly found in our series in obese pregnant women in agreement with other researcher reported $[4,5]$.

The second frequent are cardiovascular defects. Although we have small number of cases with cardiovascular defects this is of great interest because of the severity of this type of malformation. Our results are according with data reported by other authors [11,12]. A recent meta-analysis concerning maternalobesity and risk of neural tube defects included five studiesdescribing the risk associated with severe obesity,odds ratio 3.11 (95\% CI 1.75-5.46). However, for all obese mothersthe odds ratio was 1.70 (95\% CI 1.34-2.15), meaning that the

\begin{tabular}{|c|c|c|c|c|c|}
\hline Women & UW & RW & OW & OB & Total \\
\hline For newborns & 22 & 49 & 18 & 15 & 104 \\
\hline For interruptions & 13 & 69 & 14 & 17 & 113 \\
\hline Total & 35 & 118 & 32 & 32 & 217 \\
\hline Frequency & 16.13 & 54.37 & 14.74 & 14.74 & \\
\hline
\end{tabular}

Table 1: Distribution of women according to BMI.

\begin{tabular}{|c|c|c|}
\hline Systems & PB & PB(A) \\
\hline Cardiovascular & 1,31 & 2,81 \\
\hline Nervous System & 0,76 & 3,77 \\
\hline Hydrocephaly & 0,14 & 1,71 \\
\hline Neural tube defects & 0,62 & 2,05 \\
\hline Digestive tracts & 0,76 & 2,12 \\
\hline Genitourinary & 1,31 & 2,12 \\
\hline Skeletal disorders & 1,79 & 2,26 \\
\hline Syndromes & 0,55 & 1,30 \\
\hline
\end{tabular}

PB: Prevalence at birth (malformed new born/14.481); PB (A): Prevalence at birth adjusted $\{$ (malformed new born + malformed fetus $) / 14.594\}$.

Table 2: Prevalence at birth (in percent) of congenital malformations from 2004 to 2008

\begin{tabular}{|l|c|c|c|c|}
\hline Congenital defects. & UW & RW & OW & OB \\
\hline Cardiovascular defects & 2 & 8 & 3 & 4 \\
\hline Septal defects & 2 & 4 & 0 & 3 \\
\hline Transposition of the great vessels & 3 & 5 & 3 & 4 \\
\hline Complex cardiopathies & 7 & 17 & 6 & 11 \\
\hline Subtotal & 20,00 & 14,40 & 18,75 & 34,38 \\
\hline Frequency & \multicolumn{4}{|l}{} \\
\hline Neurological detects & 4 & 12 & 5 & 4 \\
\hline Hydrocephaly & 1 & 17 & 4 & 8 \\
\hline Neural tube defects & 1 & 0 & 0 & 0 \\
\hline Others & 6 & 29 & 9 & 12 \\
\hline Subtotal & 17,14 & 24,57 & 28,12 & 37,50 \\
\hline Frequency & & & & \\
\hline
\end{tabular}

Table 3: Most frequent congenital defect distribution of newborns and fetuses according to mothers' BMI.

\begin{tabular}{|l|l|l|l|l|}
\hline Congenital defects & UW & RW & OW & OB \\
\hline Esophageal atresia & 1 & 1 & 2 & 1 \\
\hline Small gut atresia & 0 & 3 & 0 & 0 \\
\hline Abdominal wall defects & 1 & 9 & 1 & 0 \\
\hline Orofacial clefts & 0 & 2 & 0 & 2 \\
\hline Imperforateanus, & 1 & 1 & 0 & 1 \\
\hline Intestinal malrotation and obstruction & 0 & 0 & 1 & 0 \\
\hline Others & 0 & 2 & 1 & 1 \\
\hline Subtotal & 3 & 18 & 5 & 5 \\
\hline \% & 8.57 & 14.41 & 15.62 & 15.62 \\
\hline Cystic kidneys & 2 & 3 & 1 & 2 \\
\hline Hydro nephrosis & 1 & 5 & 1 & 0 \\
\hline Hypospadia & 1 & 5 & 0 & 0 \\
\hline Hydrocele & 1 & 4 & 0 & 0 \\
\hline Others & 3 & 3 & 0 & 1 \\
\hline Subtotal & 8 & 20 & 2 & 3 \\
\hline \% & 22.85 & 16.95 & 6.25 & 9.37 \\
\hline Preaxial polydactyly, & 0 & 3 & 0 & 1 \\
\hline Postaxial polydactyly, & 2 & 2 & 3 & 0 \\
\hline Pes equinovarus, & 1 & 8 & 1 & 3 \\
\hline Limb reduction defects & 3 & 3 & 0 & 0 \\
\hline Oligo amnios & 1 & 1 & 0 & 1 \\
\hline Others & 2 & 0 & 0 & 0 \\
\hline Subtotal & 9 & 17 & 4 & 5 \\
\hline \% & 25.71 & 14.40 & 12.50 & 15.63 \\
\hline Chromosomal aneuploidy & 0 & 13 & 4 & 2 \\
\hline Other congenital defects & 4 & 11 & 1 & 1 \\
\hline Subtotal & 4 & 24 & 5 & 3 \\
\hline \% & 11.42 & 20.33 & 15.63 & 9.37 \\
\hline Table 4: & & & 0 & \\
\hline
\end{tabular}

Table 4: Less frequent congenital defect distribution of newborn and fetus according to mothers' BMI. 
Citation: Fernández RAH, Collazo LV, Hernández SC, Cruz AL (2015) Relationship between Maternal Obesity and Congenital Malformation in a Subpopulation of Havana. J Diabetes Metab 6: 498. doi:10.4172/2155-6156.1000498

risk formothers with more severe obesity was thus nearly twice. In addition obese women had an increased risk for hydrocephaly, cardiac defects, and other defects, however, not all defects have been associated with maternal weight [13].

\section{Conclusions}

Our study reinforces the idea that obesity during pregnancy becomes a high risk for congenital malformation in the offspring, in particular cardiovascular and neural tube defects.

\section{References}

1. Siega-Riz AM, Siega-Riz AM, Laraia B (2006) The implications of maternal overweight and obesity on the course of pregnancy and birth outcomes. Matern Child Health J 10: 153-156.

2. Gilboa SM, Correa A, Botto LD, Rasmussen SA, Waller DK, et al. (2010) Association between prepregnancy body mass index and congenital heart defects. Am J Obstet Gynecol 202: e1-10.

3. Katherine J, Stothard KJ, Tennant PW, Bell R, Rankin J (2009) Maternal Overweight and Obesity and the Risk of Congenital Anomalies. A Systematic Review and Meta-analysis. JAMA 301: 636-650.

4. Shaw GM, Velie EM, Schaffer D (1996) Risk of neural tube defect-affected pregnancies among obese women. JAMA 275: 1093-1096.

5. Cedergren MI, Kallen BA (2003) Maternal obesity and infant heart defects. Obes Res 11: 1065-1071.
6. Stott-Millera M, Heike CL, Kratz M, Starr JR (2010) Increased risk of orofacial clefts associated with maternal obesity: case-control study and Monte Carlobased bias analysis. PaediatrPerinatEpidemiol 24: 502-512.

7. Stothard KJ, Tennant PWG, Bell R, Rankin J (2009) Maternal Overweight and Obesity and the Risk of Congenital Anomalies. A Systematic Review and Metaanalysis. JAMA 301: 636-650.

8. Blomberg MI, Kallen B (2010) Maternal Obesity and Morbid Obesity: the Risk for Birth Defects in the Offspring. Birth Defects Research (Part A) 88: 35-40.

9. McMahon DM, Liu J, Zhang H, Torres ME, Best RG (2013) Maternal Obesity, Folate Intake, and Neural TubeDefects in Offspring. Birth Defects Research (Part A) 97: 115-122

10. Cai G, Sun X, Zhang L, Hong Q (2014) Association between maternal body mass index andcongenital heart defects in offspring: a systematic review. Amer J Obstet\&Gynecol 205: 91-117.

11. Watkins ML, Rasmussen SA, Honein MA, Botto LD, Moore CA (2003) Materna Obesity and Risk for Birth Defects. Pediatrics 111; 1152-1158.

12. Rankin J, Tennant PWG, Stothard KJ, Bythell M, Summerbell CD, et al. (2000) Maternal body mass index and congenital anomaly risk: a cohort study. International Journal of Obesity ad 34: 1371-1380.

13. Rasmussen SA, Chu SY, Kim SY, Schmid CH, Lau J (2008) Maternal obesity and risk ofneural tube defects: a metaanalysis. Am J Obstet Gynecol 198: 611 619. 